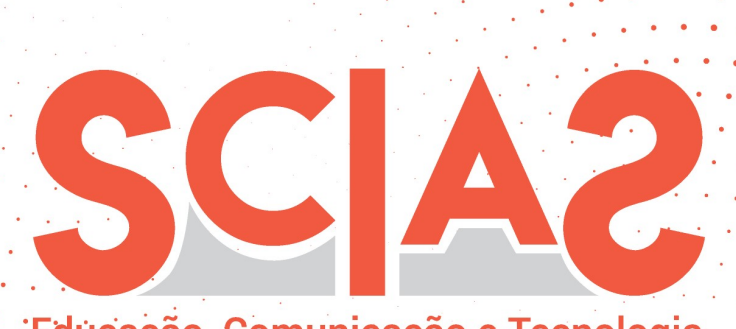

Educcaçãăo, Comunicação e Tecnologia

Atribuição BB CY 4.0

\title{
Ensino de literatura e isolamento social: aulas em tempos de COVID-19 - Entrevista com a professora-pesquisadora mestra Fernanda Rodrigues de Figueiredo
}

\author{
Gustavo Tanus Cesário de Souza ${ }^{1}$ \\ Fernanda Rodrigues de Figueiredo ${ }^{2}$
}

“Que potenciais conhecimentos decorrem da pandemia do coronavírus?” (Boaventura de Sousa Santos).

"Estou preocupada com as populações que se encontram sempre sujeitas a diferentes formas de repressão e que são muito mais vulneráveis durante este período de resposta falha ao coronavírus". (Angela Davis).

\section{Apresentação}

Nestes tempos, com uma modificação abrupta e impremeditada nas relações sociais humanas devido ao agravamento da crise sócio-político-econômica causado pela pandemia da COVID-19, que forçou a adoção de medidas de

\footnotetext{
${ }^{1}$ Doutorando em Estudos da Linguagem / Leitura do texto literário e Ensino, pela UFRN, com intercâmbio na Faculdade de Educação da UFMG. Mestre em Teoria da Literatura e Literatura Comparada, pela UFMG. Bacharel e licenciado em Estudos Literários/Língua Portuguesa, e Bacharel em Edição, pela UFMG. Pesquisador do Núcleo de Estudos Interdisciplinares da Alteridade (FALE/UFMG), e do Moviola grupo de estudos de literatura, cinema e outras artes. Colaborador do site literafro - $\mathrm{O}$ Portal da Literatura Afro-brasileira, onde integra o comitê editorial. É autor dos livros "Africanos e afrodescendentes nas estantes: a Biblioteca Pública Estadual de Minas Gerais" (Fale/UFMG, 2017) e "A Hagbe que nos guarde..." (Editora IFRN, 2019).

E-mail: gustavotcs@gmail.com

${ }^{2}$ Mestra em Estudos Literários pela Faculdade de Letras da Universidade Federal de Minas Gerais(Fale/UFMG, 2009), é bacharela em Letras e licenciada em Língua Portuguesa pela mesma universidade. Possui, ainda graduação em Pedagogia, com especialização em Educação Tecnológica Inclusiva, Sexologia, Novas tecnologias (em curso), Gestão escolar, Supervisão e orientação escolar, Neuropsicopedagogia, Pedagogia Digital e Inovações tecnológicas. É, atualmente, professora visitante no IFMG, Campus Ribeirão das Neves, e docente efetiva na Educação Básica da Rede Pública Estadual de Ensino de Minas Gerais. Pesquisadora do Núcleo de Estudos Interdisciplinares da Alteridade da Faculdade de Letras da UFMG, possui dezesseis anos de experiência em docência e pesquisa na área de Letras.

E-mail: nandarf_afro@yahoo.com.br
} 
distanciamento social e quarentena, têm sido colocado enormes desafios, inclusive para as escolas. Tais desafios vêm interferindo (e continuarão interferindo) na vida de estudantes, professores, modificando os modos de estruturação das atividades didático-pedagógicas, colocando obstáculos para a desenvolvimento do processo de ensino-aprendizagem, óbices que começam a delinear alentadas questões para a educação contemporânea.

Para o entendimento das questões, pensamos a entrevista com a professora e pesquisadora Mestra Fernanda Rodrigues de Figueiredo, no diálogo em que a escutaremos sua voz sobre a docência em tempos de isolamento social necessário, buscando escutar as reflexões da docente com relação às políticas públicas sobre educação a distância e sua dinâmica político-pedagógica. É tempo de aprender com essa professora da educação pública brasileira, com experiência/vivência de mais de 15 anos de sala de aula, o que implica estudo, pesquisa, para o ensino de leitura e produção de textos, e ensino de literatura, que é foco das nossas pesquisas.

Fernanda Rodrigues de Figueiredo é Bacharela e licenciada em Letras/Português, pela Universidade Federal de Minas Gerais (UFMG), é graduada também em Pedagogia. Mestra em Estudos Literários pela UFMG, tendo defendido a dissertação $A$ mulher negra nos Cadernos Negros: autoria e representações, que é a primeira a estudar as escritoras contistas publicadas nos Cadernos negros, importante publicação do coletivo Quilomb hoje de escritoras e escritores afro-brasileiros que, desde 1978, vem editando, em antologia coletiva, livros de poemas e contos desses escritores. Fernanda é, também, pesquisadora do Núcleo de Estudos Interdisciplinares da Alteridade da Faculdade de Letras - Universidade Federal de Minas Gerais (NEIA/FALE/UFMG), tendo produzido artigos, críticas literárias, e participado, como coautora,dos livros sobre a literatura afro-brasileira e ensino de literatura Literatura afro-brasileira: abordagens na sala de aula e Literatura afrobrasileira: 100 autores do século XVIII ao XXI, projeto coordenado por Eduardo de Assis Duarte, publicado pela Editora Pallas. 
A professora tem buscado especializar-se, aperfeiçoar-se e atualizar-se, antecipando questões que viriam a ser decisivas para a educação de hoje, tais como: Educação Tecnológica Inclusiva; Novas tecnologias; Pedagogia Digital e Inovações tecnológicas; Educação a Distância; e Neuropsicopedagogia. Nestas especializações e aperfeiçoamentos, ela buscou ampliar reflexão em temáticas universais e atemporais, quando se trata de jovens estudantes, tais como Sexologia; Prevenção ao uso de drogas; Qualificação para correção de redações ENEM; além de pensar na administração da instituição escola, tendo estudado Gestão escolar; Supervisão e Orientação escolar. Produziu e trabalhou como consultora de materiais didáticos sobre Cultura Africana, foi educadora Projovem Urbano na Fundação de Desenvolvimento da Pesquisa (FUNDEP), entre outras atividades. Coordena projetos voltados ao ensino e à extensão: Oficina de Redação Tecnológica aplicada: textos acadêmicos e uso de novas tecnologias, e EaD: redação e interpretação de textos foco Enem e concursos, em que movimenta, junto dos estudantes, educação, artes, cidadania, nas modalidades Leitura e produção de textos - técnicos e artísticos. Desde 2018 é professora visitante no IFMG, Campus Ribeirão das Neves, lugar onde tem desenvolvido outros projetos de extensão e ensino de literatura.

Gustavo Tanus Cesário de Souza: Por experiência comum, partilhada, vão se estabelecendo elos, enredamentos de um tecido de inteligências e sensibilidades, não mais por experimentação da compaixão (que também é necessária). Nesse sentido, em seus caminhos pelos estudos, percebemos a continuação de um coerente projeto que busca entender, entre outras coisas, os processos de representação/representatividade, de lugar de fala, de desenvolvimento da cidadania. Em um ensaio sobre a obra da escritora Jussara Santos você cita uma fala dela em que ela diz ter realizado, com/em sua obra, uma "reversão do centro",que, como centro da questão, é a escuta da voz da periferia, da própria voz. Pensando sua própria trilha, como você, professora, entende essa reversão do centro, como escritora, pesquisadora, quanto na esfera humana, sendo mulher e mãe? 
Fernanda Rodrigues de Figueiredo: Acredito que a reversão do centro é a visibilidade de pessoasque sempre foram relegadas na sociedade.A maior dificuldadeem ser mulher preta é enfrentar constantemente a acusação de ser mulher negra.É como se não houvesse nenhuma trilha feita pra nós. Estradas, ruas, nada! A solidão profunda de ser alguém deslocada, uma peça sem encaixe, sem lugar no mundo. Os olhares ou nos condenam ou nos desprezam ou se apiedam de nós. Tem um trecho do romance As mulheres de Tïucopapo (1982), livro de estreia da escritora pernambucana Marilene Felinto que reflete bem o que eu digo sobre esse nosso "lugar":

É difícil até acreditar que serei capaz de ir até o fim. Pouca gente foi. E isso torna tudo mais árduo. Além de que, essa pouca gente que foi não deixou passos, uma trilha feita. Mas nenhuma trilha feita me serviria também. Devo abrir a cortes minha própria linha na mata, devo fazê-la eu só. Trilha nenhuma outra me serviria. E isso torna tudo mais árduo (FELINTO, 1992, p. 94).

Esse pensamento de Felinto foi epígrafe em minha dissertação de mestrado em 2009. As palavras dela continuam muito vivas em mim. E, por isso, só vislumbro um caminho para a mudança real: o chamamento à ação. Ações constantes e ininterruptas de luta pela inclusão de cada pessoa. Não se pode ignorar a dor do outro. E não se pode descansar enquanto houverem pessoas sofrendo.Eu ouço às vezes, pessoas privilegiadas dizendo não querer se envolver para não sofrer, por que não podem consertar o mundo.E quando ouço isso é uma grande ofensa. Como pode?Conseguir não se envolver?Simplesmente não sentir o outro?E enquanto agonizam, vamos meditar em prol de manter a paz interior?A mesma paz hegemônica calcada no privilégio historicamente construído. Acredito ferozmente que todos devem se envolver e lutar. E nunca descansar na ideia utópica egocêntrica de que fizeram o bastante. A luta deve ser constante. Nós nunca fizemos o bastante.

\section{Gustavo Tanus Cesário de Souza: Quais foram as principais mudanças na forma de desenvolver suas atividades de docência, no regime de trabalho remoto, por conta da pandemia da COVID-19?}

Fernanda Rodrigues de Figueiredo: Desde sempre a busca pela sobrevivência. Sempre trabalhei em dois empregos (até três se contar os bicos 
finais de semana - risos), então o estar em casa não era opção. Sempre fuiquase visita na minha própria casa:se você quisesse esconder de mim era só fica na minha casa (risos). Eu nunca frequentei tanto minha casa. Para contextualizar: Moro no lote onde tem quatro casas: todas oriundas da construção original que mãe - mulher preta costureira - foi fazendo sozinha enquanto criava os três filhos pós separação. É cá em Santa Luzia/MG, região periférica da capital Belo Horizonte. Ser professora foi uma escolha que nasceu quando estava eu com 13 anos. E isso se deu por que minha trajetória na escola (na verdade a trajetória de mãe e de minha irmã também) foi sofrida. Jurei que eu faria melhor, que a trajetória das minhas alunas e meus alunos seria melhor. Queria tirar a dor pelo menos na escola.

As aulas foram suspensas dia 18/03 e dia 31/o3 comecei a dar aula online a pedido dos meus alunos. Estavam apavoradas/os e recebi várias mensagens por telefone. Uma amiga falou-me do Telegram como ferramenta. Busquei informações e "fucei" (bem típico de professor isso - risos). Criei canais e grupos para estabelecer uma plataforma dialógica e interativa de ensino. Organizamos rotina e combinados bem claros. Explico os porquês de tudo para eles. Atualmente tenho:

- Duas turmas de $7^{\circ}$ ano= São 73 alunos listados. Participando e fazendo atividades $=55$ alunos.

- Turma $2^{\circ}$ ano do E.M.= Temos 37 listados. Participando e fazendo atividades $=32$ alunos.

- Turma $3^{\circ}$ ano do E.M.= Tínhamos 28 listados. Participando e fazendo atividades $=27$ alunos.

Todos esses discentes estão no Telegram. É o "App” mais leve e com mais recursos para a educação hoje. Eles estão reagindo bem. Simplifiquei tudo o possível. Poucos veem as aulas ao vivo. Entendo que alguns por não terem condições (trabalho, outras tarefas, falta internet suficiente) e outros por não dominarem os recursos ou não ter ainda entendido o sistema.A escola tem postado nas redes, enviado mensagens, a diretora disponibiliza seu próprio Whatsapp, eu e muitos colegas também, atendemos e encaminhamos.Eu pedi as listas e liguei para os pais/responsáveis e alunos. Todo mês ligo para os que 
somem e os que ainda não estão conectados. Esse movimento é bem difícil, porque as realidades são diversas: estrutura familiar, de apoio, de acesso. Enviei e-mails para os governos com propostas de intervenção. Nunca responderam.

O senso comum e também alguns professores de Língua Portuguesa ainda acreditam que essa disciplina é puramente técnica/teórica, ou seja, para ser "aula de português" tem que ter uma decoreba de regra, uma tabela de conjugação verbal... coisas desse tipo. Isso é o maior prejuízo ao ensino aprendizagem desse componente curricular. Afasta o interesse pela aprendizagem. Quando eu pego uma turma pela primeira vez, ouço as reclamações sobre terem "trauma" de copiar e responder somente atividades do livro didático e até textos. Partilho do mesmo trauma, pois meus professores faziam isso lá nos anos 1980 e 1990. Não compreendo os porquês de não haver evolução nessas metodologias, já que os resultados são péssimos. Eu subverto TOTALMENTE. Faço planejamento seguindo todos os documentos oficiais como a BNCC, por exemplo. No entanto, a minha metodologia não é nada tradicional. E funciona super bem, pois o avanço dos alunos é notável em 3 meses de trabalho. No planejamento busco organizar um tema sociocultural por mês e abordar os conteúdos sequenciados a partir desse tema escolhido. Vou dar um exemplo:

Primeiro a escolha dos textos. Veja bem, os textos dos livros didáticos e até as escolhas dos professores, geralmente vão pelo olhar - desculpe vou usar a fala dos estudantes - "chato". Penso, grosseiramente, na minha aula como venda de produtos: precisa ser algo atrativo e útil para o público. Então, estudo primeiro o público: gostos, redes sociais deles (verdade, trocamos muita ideia nas redes, eu curto e comento as postagens deles, dou conselhos, estabeleço laços afetivos). Então, digamos, se preciso trabalhar verbo, vou escolher letra de música que os alunos curtem e um poema que eu curto que falem da mesma temática. Fica assim:

Tema: Preconceito.

Tópico gramatical: verbos.

Texto 1: “É o poder”, de KarolConká (música).

Texto 2: “Ao pé do ouvido", de Jussara Santos (poema). 
Aqui aplico atividades sobre usos de linguagem coloquial e culta-padrão, como as vozes poéticas falam do enfrentamento do preconceito e sexismo, uso dos verbos e o significado de cada um (como são colocados nos dois textos e os efeitos de sentido que alcançam ali).

Dois textos curtos e ricos pra "pensar" a língua e não decorar que verbo é a palavra que designa ação, estado ou fenômeno da natureza". Coisa essa que os estudantes vão esquecer em $3,2,1$ !

Lembrando que não apresento os textos somente para ler e sim sentir. No material, que é todo interativo, tem figurinhas para clicar e abrir o videoclipe com a música, minha videoaula e meus podcasts (áudios explicativos) para cada atividade. Aprendi mais usos de tecnologias no IAPEMI (Instituto de Atendimento Pedagógico Multidisciplinar Integrado) e aplico nos materiais. A ideia é simular a presença da professora ali ao lado dos estudantes. Essas adaptações dão trabalho, mas os resultados são maravilhosos. O feedback dos discentes tem enchido meu coração de esperança.

\section{Gustavo Tanus Cesário de Souza: Em que esse isolamento social, como para contenção da propagação desse vírus mortal, se assemelha a outras formas de isolamento, investidos nas alteridades, mulheres, negras, professoras?}

Fernanda Rodrigues de Figueiredo: Aqui em casa costumamos conversar muito, principalmente Marina e eu. Além de irmãs também somos sócias em uma empresa que começou em janeiro desse ano. Como tantas outras empresas estamos sofrendo com essa situação de sobreviver à crise que é mundial. Empreender nesse país é difícil. Duas mulheres pretas pobres se lançarem na tarefa é missão de conquista do impossível mesmo. (risos)

Essa pandemia fez evidenciar as diferenças. Dentre tantas outras coisas e o pavor uma parcela da população exibe seus privilégios nas redes e mídias. Relatam desafios conciliar trabalho casa filho obrigações com casa, família. 
Agora estão experimentando parcialmente (levemente, já que a realidade social é bem diferente) aquilo que nós mulheres negras pobres já vivemos há muito tempo.

Eu fico pensando e me lembrando sempre de Lélia Gonzalez, Angela Davis, Patricia Collins que abordaram essa questão do feminismo $\mathrm{X}$ feminismo negro e Mulherismo Africana, da distância entre as pautas hegemônicas e as nossas. As classes socialmente beneficiadas estão totalmente deslocadas da realidade da maior parte da população que é pobre. Diante de todo esse cenário muitas irmãs e irmãos estão aí numa situação ainda mais grave: agruras e escassez de tudo, não é mesmo!? Nós ainda estamos conectados, temos uma casa própria, imagina tantas pessoas que moram nas ocupações, nas favelas, nas ruas. Tantos outros desafios de sobrevivência a mais que nós. Então, a gente percebe que enquanto uns podem discursar, do Alto do seu privilégio,sobre Marxismo, neoliberalismo, racismo, feminismo, tem quem "vive" a dor de tudo isso açoitando na lida. É cômodo analisar textos e escrever artigos, publicarem conteúdo e críticas sem nunca conhecer os rostos das alteridades de quem estão falando em seus discursos. As alteridades têm rostos, nomes, vidas e então isoladas desde sempre. Isolamento que é doloroso. Agora todo mundo está isolado experimentando talvez $10 \%$ do que a população não branca pobre vive na pele. Então, eu percebo que é uma oportunidade única para humanidade. Se aproximar querer se envolver com pessoas que até então eram invisíveis.

O desprezo da sociedade com relação ao professor a professora que enfrenta diariamente 1000 desafios para tentar estabelecer o mínimo de contato com conhecimento, porque nós atendemos comunidades escolares carentes de tudo: falta de conhecimento, condições mínimas básicas. Professoras que compartilham com tamanha generosidade e compromisso e mereciam respeito.

Ano passado, ouvi numa apresentação em Ouro Preto, a maravilhosa Luana Tolentino narrar que certa vez foi acusada por uma "amiga" privilegiada, professora em outra rede de ensino, de ser apenas uma "professorinha de bairro". Já ouvi coisas semelhantes como: "Mas você tendo tento estudo e esse currículo ainda dá aula em escolinha estadual do bairro?” 
É uma acusação que quando não em palavras tão explícitas também vem em insinuações, nãos... Claramente duvidam da nossa capacidade. Respondo como a incrível Tolentino: "- Sou professorinha de bairro como muito orgulho". Somente a experiência nas comunidades carentes faz com que saibamos o que é a educação. Não quero desmerecer outras experiências de docência não. No entanto, só consegui "sentir" a realidade quando vivenciei lado a lado com essas comunidades carentes (do Poca ói, Sumaré, Pedreira, Novo Aarão Reis, Palmital, Caveirinha). Aprendi demais também com as colegas do magistério, cujas vidas foram dedicadas as periferias. Se eu sei alguma coisa sobre educação eu devo a essas comunidades. Elas me ensinaram a sentir e ver para além da academia e da ciência. As universidades seriam bem mais eficientes se estivessem abertas empirismo, ao trabalho de campo dentro das comunidades.

\section{Gustavo Tanus Cesário de Souza: O que orienta o seu trabalho como professora? O que passou a orientar, nestes últimos tempos?}

Fernanda Rodrigues de Figueiredo: Eu costumo dizer que ser professora é ensinar a ter coragem.Alguns querem categorizar de polêmica ou exótica. Designações que são, na minha nem tão humilde opinião (risos), bem preconceituosas. Prefiro dizer que sou combativa. Gosto bastante de uma frase de Luiz Gama: "Só rendo obediência à virtude e à inteligência". Nem todo mundo que leciona é professor. Pode estar professor, viver disso e não ser.Porque ser é essência, é constructo, é formação identitária. Para mim ser professor depende de três qualidades essenciais:

1. Ler e compreender: contextos, textos, você mesmx, as pessoas

2. Capacidade de aprender e continuar aprendendo

3. Questionar sempre: A si mesmx, as ordens, os textos, a história, as pessoas e os contextos.

Escrevi recentemente um TCC para minha especialização em AEE pelo IFTMG [Atendimento Educacional Especializado, pelo Instituto Federal do Triângulo Mineiro], no qual cunho conceito "Educação Afrotransgressora". A Educação Afrotransgressora vai de mãos dadas com a liberdade vivenciada, poisé um 
conceito empírico desenvolvido como metodologia de ensino-aprendizagem. Defende uma educaçãopautada centralmente pela filosofia Ubuntu (africana) e sustentada por quatro pilares sejam eles a humanitude, a dororidade, a sustentabilidade e o mulherismo.

A Educação Afrotransgressora propõe teorias e práticas pedagógicas que questionam posicionamentos tradicionalistas opressores. Tais práticas criam uma reconstrução da sociedade via sala de aula. É a educação como centro da evolução humana, econômica, cultural e social. Essa é o que baliza minha atuação docente hoje e sempre.

\section{Gustavo Tanus Cesário de Souza: Temos convivido com a suspensão} das atividades presenciais nas escolas brasileiras, por conta da necessidade de isolamento social, e a migração das atividades presenciais para o ensino remoto. Quais têm sido as consequências disso para a Fernanda, mulher/mãe/pesquisadora/professora? Quais as implicações de uma possível migração das escolas presenciais para a EaD?

Fernanda Rodrigues de Figueiredo: Preocupação. Tensão constante. Atendimento quase 24 horas aos alunos e pais que se sentem abandonados e perdidos. As mães estão realmente sofridas. Porque a cobrança social é cruel contra as mulheres. Eu tenho uma rede de apoio realmente incrível: mãe, irmãos e cunhada. Destaco o companheirismo de Anderson, pois realmente seria ainda mais impossível para mim sem esse essencial apoio. Ele faz tudo em casa: lava, passa cozinha, cuida da filha. A questão é que homem algum é completamente desconstruído, entende. A influência da educação familiar e social essencialmente machistas é brutal. Ele costuma reclamar que eu, muitas vezes, dou aula até pra ele (risos). É que não se pode reformar o prédio sem arrumar cada espaço. E precisamos começar em nosso lar.

Não creio na migração das escolas presenciais para EaD. Os atuais governos são alienados sim. Estão economizando com as escolas fechadas e não duvido da capacidade deles de precarizar ainda mais a educação já sucateada. Todavia, a 
pressão da sociedade será maior, acredito, e assim que a pandemia passar voltaremos ao presencial. O problema é que teremos que continuar realizando [ensino remoto] EaD mesmo que parcialmente, já que recuperar um ano letivo é tarefa que nos custará, no mínimo, cinco anos. Os estudantes precisarão de todos os esforços de nossa parte. E precisamos nos responsabilizar por isso.

Nas palavras de Hannah Arendt (1906-1975) "A educação é o ponto em que decidimos se amamos o mundo o bastante para assumirmos a responsabilidade por ele". Devemos assumir essa responsabilidade mesmo que estejamos todos de algum modo fraturados.

\section{Gustavo Tanus Cesário de Souza: Você considera que a literatura contribuiu para a expressão da alteridade? $E$, hoje, qual é a contribuição?}

Fernanda Rodrigues de Figueiredo:Os estudos culturais, a literatura de expressão da alteridade, os trabalhos científicos foram essenciais para o fortalecimento das lutas sociais nesse país e no mundo. Não se pode negar. E hoje a visibilidade dos trabalhos das críticas das leituras a respeito da literatura de expressão da alteridade propiciam aquisição de competências e habilidades centrais para a construção de repertório sociocultural e linguístico realmente produtivo.

O ensino aprendizagem de Literatura, por exemplo. A literatura é uma arte presente no dia a dia (em músicas, frases, mitos, causos e narrativas) e pode se tornar um excelente argumento para iniciar debates sobre importantes temas como o preconceito e exclusão. A literatura pode, ainda, ajudar na integração das disciplinas, pois em suas linhas é possível vislumbrar questões históricas, sociais, artísticas, estéticas, biológicas e científicas. Portanto, ela pode se tornar a porta de entrada para uma revisita à História brasileira e universal, um caleidoscópio crítico sob pontos obscuros e negligenciados. 
Assim como em várias outras áreas do conhecimento e da sociedade, vemos na literatura algumas negligencias, personalidades obscurecidas pelo preconceito e, por vezes, tais homens e mulheres são geniais e passam despercebidos.

Apontar um caminho para o ensino de Literatura Afro-Brasileira na escola é um desafio que o professor de Língua Portuguesa deve aceitar. Sabemos que a lei ${ }^{o}$ 10.639/2003, ao incluir no currículo oficial da Rede de Ensino a obrigatoriedade da temática "História e Cultura Afro-Brasileira" nos impõe tal desafio. Para que possamos ter êxito é necessário expor a história e cultura afro e então a literatura; formar uma rede para ler e ouvir mitos africanos, contos e poemas afro-brasileiros e, finalmente, incentivar a produção de textos do alunado. Promover o conhecimento e a valorização da cultura oral característica marcante da cultura africana e Afro brasileira -, bem como, aprimorar a capacidade de escrita dos alunos.

\section{Gustavo Tanus Cesário de Souza: Como professora-pesquisadora de literatura, diga-nos, por que há uma distância entre a produção literária e a educação?}

Fernanda Rodrigues de Figueiredo: Existe um abismo gigantesco. Veja bem, a produção literária proveniente dos espaços periféricos é incrivelmente rica. Temos produções que precisam chegar ao público urgentemente, pois fariam uma revolução magistral nas mentalidades, digo inclusive mudanças sociais de ressignificação dos espaços e oportunidades e empoderamento do povo brasileiro. Mas...esse mas nos persegue (risos). Como chegar na população? Alguns dirão: livro é caro. Verdade. No entanto, brasileiros simplesmente não consomem literatura (como nós professores queremos) porque não tem hábito. Meus alunos sempre dão jeito de ler livros em pdf e audolivro quando solicito leituras. E sabe qual é a primeira coisa que fazem depois? Perguntar onde compram o livro, porque querem "ter" o livro. Juntam o dinheiro e compram seus livros e ficam maravilhados. Isso vira uma prioridade para elas e eles. Então, o mercado deveria se aproximar dos professores da periferia para que esses fossem os agentes de campo da disseminação da literatura. Seria uma revolução linda! 
Gustavo Tanus Cesário de Souza: A ativista Cindy Wiesner, no livro recente de Angela Davis, Construindo movimentos: uma conversa em tempos de pandemia, afirmou que "Podemos ser os defensores da vida dos territórios e dos conhecimentos e também fazer saber que há alternativa." (WIESNER, 2020, posição 275), para você, em relação à educação, especificamente ao ensino de literatura, qual é a alternativa?

Fernanda Rodrigues de Figueiredo: Sair dos muros da universidade. Ultrapassar as paredes dos castelos de cristal da Disney universitária. Estar lado a lado com quem está na linha de frente da luta: professores de bairro, professores da educação básica. Não adianta a pompa e circunstância academicista, porque nenhum topo se sustenta sem a base.Para bellhooks(2017, p. 273):

[...] o aprendizado é um lugar onde o paraíso pode ser criado.A sala de aula, com todas as suas limitações, continua sendo um ambiente de possibilidade nesse campo de possibilidades. Temos a oportunidade de trabalhar pela Liberdade para exigir de nós e de nossos camaradas uma abertura do coração que nos permite encarar a realidade ao mesmo tempo em que coletivamente imaginamos esquemas para cruzar fronteiras para transgredir. Isso é educação como prática da Liberdade.

Temos que lutar em campo pela liberdade de cada pessoa nessa sociedade desigual.

Gustavo Tanus Cesário de Souza: Sabemos que professores são, antes de tudo, leitores; diante disso, quais livros (de literatura) você está lendo neste momento?

Fernanda Rodrigues de Figueiredo: Muita literatura afro, indígena e afroculturismo. Ali na cabeceira estou com a antologia Ócios no ofício,com organização de Karine Oliveira (2020) e os livros Ritos de Passagem (Giostri, 2014), O Caçador Cibernético da Rua 13 (Malê, 2017) eA cientista guerreira do facão furioso (Malê, 2019), estes de Fábio Kabral. Apaixonada demais.O afrofuturismo pode revolucionar a forma como os jovens negros se veem 
representados. Dá a eles uma nova perspectiva. Se isso existisse no meu tempo de criança e jovem... nossa, minha vida teria sido outra!

Gustavo Tanus Cesário de Souza: Professora, sua contribuição para o entendimento do uso das tecnologias para o ensino-aprendizagem de literatura, para continuação do debate sobre ensino a distância foi muito importante para nós. Agradecemos imensamente a sua disponibilidade e gostaríamos de deixar um espaço, caso você queira fazer algumas outras considerações.Esteja, então, à vontade para falar suas palavras finais nesta entrevista.

Professora Fernanda Rodrigues de Figueiredo: Quero fazer um chamamento à luta. Todas, todos, todes que queiram evitar a derrocada definitiva da sociedade: levantem-se e lutem todos os dias. Comecemos por nós mesmos. Reconhecendo os privilégios e buscando se engajar de verdade nas lutas sociais. Saia do lugar que limita sua visão e suas ações. Sinta o outro. Seja Ubuntu. "Uma pessoa é uma pessoa por causa das outras pessoas”. (Ditado sul africano da tribo Ubuntu).

\section{Bibliografia da professora-pesquisadora}

FIGUEIREDO, Fernanda Rodrigues de. A mulher negra nos Cadernos Negros: autoria e representações. 128 f. Dissertação (Mestrado em Estudos Literários) Faculdade de Letras, Universidade Federal de Minas Gerais, Belo Horizonte, 2009. (Dissertação).

FIGUEIREDO, Fernanda Rodrigues de. Artesanato Poético: a Valorização da Periferia. literafro, $\quad$ s. $\quad$ d. $\quad$ Disponível em: < http://www.letras.ufmg.br/literafro/autores/504-artesanato-poetico-avalorizacao-da-periferia-critica>. Acesso em: 23 jul. 2020. (Resenha crítica).

FIGUEIREDO, Fernanda Rodrigues de. Despertando os seis sentidos: no embalo literário de Fausto Antônio. literafro, s. d. Disponível em: <http://www.letras.ufmg.br/literafro/index.php?option=com_content\&view=a rticle\&id=1041\&catid=14>. Acesso em: 20 jul. 2020. (Resenha crítica).

FIGUEIREDO, Fernanda Rodrigues de. Jussara Santos. In: DUARTE, Eduardo de Assis (Coord.). Literatura afro-brasileira: 100 autores do século XVIII ao XXI. Rio de Janeiro: Pallas, 2014. p. 239-240. (Livro). 
FIGUEIREDO, Fernanda Rodrigues de. Literatura afro-brasileira: abordagens na sala de aula. Em coautoria de Aline Alves Arruda; Cristiane Côrtes; Elisângela Aparecida Lopes; Margarete Aparecida de Oliveira. Sob a coordenação de Eduardo de Assis Duarte. Rio de Janeiro: Pallas, 2014. (Livro).

FIGUEIREDO, Fernanda Rodrigues de. O uso do LITERAFRO como ferramenta em sala de aula: práticas para o ensino de Literatura. Cefet-MG, 2008. (Artigo).

FIGUEIREDO, Fernanda Rodrigues de. Representação de Minorias: A "Reversão do Centro". literafro, s. d. Disponível em: < http://www.letras.ufmg.br/literafro/autoras/29-critica-de-autoresfeminios/555-representacao-de-minorias-a-reversao-do-centro-fernandarodrigues-de-figueiredo >. Acesso em: 23 jul. 2020. (Artigo).

FIGUEIREDO, Fernanda Rodrigues de. Você amaria uma negra? GELEDÉS Instituto da Mulher Negra, 02 dez. 2018. (Artigo).

FIGUEIREDO, Fernanda Rodrigues de. Os privilegiados. GELEDÉS - Instituto da Mulher Negra, 17 maio. 2020. (Artigo).

SANTOS, Jussara. Entrevista concedida à Fernanda Rodrigues de Figueiredo. literafro, 18 mar. 2005. Disponível em: <www.letras.ufmg.br/literafro/autoras/548-jussara-santos>. Acesso em: 19 jul. 2020. (Verbete, entrevista).

\section{Referências}

DAVIS, Angela; KLEIN, Naomi. Construindo movimentos: uma conversa em tempos de pandemia. Com participação de lideranças do RisingMajority: ThenjiweMcHarris; Cindy Wiesner; Maurice Mitchell e LoanTran. Tradução de Leonardo Martins. São Paulo: Boitempo, 2020. Ebook. (Série Pandemia Capital).

FELINTO, Marilene. As mulheres de Tïocupapo. Rio de Janeiro: Record, 1992. HOOKS, Bell. Ensinando a transgredir: a educação como prática de liberdade. 2. ed. São Paulo: WMF Martins Fontes, 2017.

KABRAL, Fábio. A cientista guerreira do facão furioso. Rio de Janeiro: Malê, 2019.

KABRAL, Fábio. O Caçador Cibernético da Rua 13. Rio de Janeiro: Malê, 2017.

KABRAL, Fábio. Ritos de passagem. São Paulo: Giostri, 2014.

OLIVEIRA, Karine (Org.). Antologia Poética Ócios no Ofício. Belo Horizonte: Venasabiertas, 2020.

SANTOS, Boaventura de Sousa. A cruel pedagogia do vírus. São Paulo: Boitempo, 2020. Ebook. (Série Pandemia Capital). 
WIESNER, Cindy. Resposta à pergunta: ao que precisamos estar mais atentos ou no que devemos pensar neste momento, enquanto observamos os efeitos do vírus ao redor do mundo? In: DAVIS, Angela; KLEIN, Naomi. Construindo movimentos: uma conversa em tempos de pandemia. Com participação de lideranças do RisingMajority: ThenjiweMcHarris; Cindy Wiesner; Maurice Mitchell e LoanTran. Tradução de Leonardo Martins. São Paulo: Boitempo, 2020. Ebook. (Série Pandemia Capital). posição 245-280. 